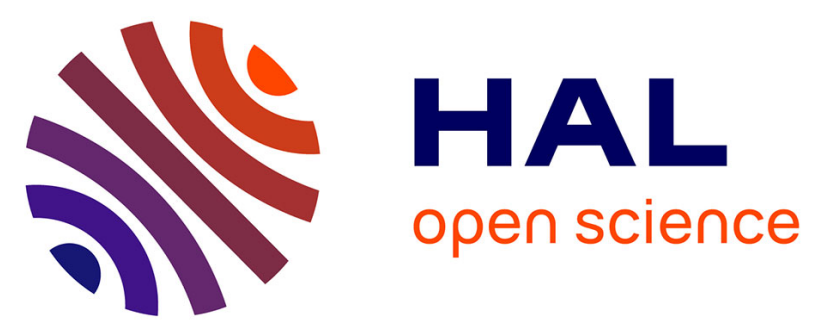

\title{
Mastectomy With Immediate Breast Reconstruction After Neoadjuvant Chemotherapy And Radiation Therapy. A New Option For Patients With Operable Invasive Breast Cancer. Results Of A 20 Years Single Institution Study \\ E. Monrigal, J. Dauplat, P. Gimbergues, G. Le Bouedec, M. Peyronie, Jl. Achard, P. Chollet, Ma. Mouret-Reynier, Jm. Nabholtz, C. Pomel
}

\section{- To cite this version:}

E. Monrigal, J. Dauplat, P. Gimbergues, G. Le Bouedec, M. Peyronie, et al.. Mastectomy With Immediate Breast Reconstruction After Neoadjuvant Chemotherapy And Radiation Therapy. A New Option For Patients With Operable Invasive Breast Cancer. Results Of A 20 Years Single Institution Study. EJSO - European Journal of Surgical Oncology, 2011, 37 (10), pp.864. 10.1016/j.ejso.2011.07.009 . hal-00732672

\section{HAL Id: hal-00732672 \\ https://hal.science/hal-00732672}

Submitted on 16 Sep 2012

HAL is a multi-disciplinary open access archive for the deposit and dissemination of scientific research documents, whether they are published or not. The documents may come from teaching and research institutions in France or abroad, or from public or private research centers.
L'archive ouverte pluridisciplinaire HAL, est destinée au dépôt et à la diffusion de documents scientifiques de niveau recherche, publiés ou non, émanant des établissements d'enseignement et de recherche français ou étrangers, des laboratoires publics ou privés. 


\section{Accepted Manuscript}

Title: Mastectomy With Immediate Breast Reconstruction After Neoadjuvant Chemotherapy And Radiation Therapy. A New Option For Patients With Operable Invasive Breast Cancer. Results Of A 20 Years Single Institution Study

Authors: E. Monrigal, J. Dauplat, P. Gimbergues, G. Le Bouedec, M. Peyronie, JL.

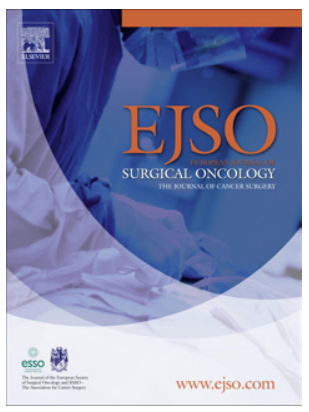
Achard, P. Chollet, MA. Mouret-Reynier, JM. Nabholtz, C. Pomel

PII:

$$
\text { S0748-7983(11)00394-5 }
$$

DOI:

$$
\text { 10.1016/j.ejso.2011.07.009 }
$$

Reference: $\quad$ YEJSO 3201

To appear in: European Journal of Surgical Oncology

Accepted Date: 25 July 2011

Please cite this article as: Monrigal E, Dauplat J, Gimbergues P, Le Bouedec G, Peyronie M, Achard JL, Chollet P, Mouret-Reynier MA, Nabholtz JM, Pomel C. Mastectomy With Immediate Breast Reconstruction After Neoadjuvant Chemotherapy And Radiation Therapy. A New Option For Patients With Operable Invasive Breast Cancer. Results Of A 20 Years Single Institution Study, European Journal of Surgical Oncology (2011), doi: 10.1016/j.ejso.2011.07.009

This is a PDF file of an unedited manuscript that has been accepted for publication. As a service to our customers we are providing this early version of the manuscript. The manuscript will undergo copyediting, typesetting, and review of the resulting proof before it is published in its final form. Please note that during the production process errors may be discovered which could affect the content, and all legal disclaimers that apply to the journal pertain. 
Mastectomy with immediate breast reconstruction after neoadjuvant chemotherapy and radiation therapy. A new option for patients with operable invasive breast cancer. Results of a 20 years single institution study.

E Monrigal*, J Dauplat*, P Gimbergues*, G Le Bouedec*, M Peyronie*, JL Achard ${ }^{* *}$, P Chollet ${ }^{* * *}$, MA Mouret-Reynier ${ }^{* * *}$, JM Nabholtz ${ }^{* * *}$, C Pomel $^{\star \circ}$

Department of Surgical Oncology*

Department of Radiotherapy**

Department of Medical Oncology***

INSERM Unit $990^{\circ}$

Jean Perrin Comprehensive Cancer Centre

Correponding author:

christophe.pomel@cjp.fr

58 rue Montalembert

63011 Clermont-Ferrand Cedex 1

France 


\section{ABSTRACT}

Purpose

To evaluate the feasability of immediate breast reconstruction (IBR) following mastectomy after neoadjuvant chemotherapy (NACT) and radiation therapy (RT) for operable invasive breast cancer (OIBC), in terms of incidence of local complications, locoregional control and survival.

Patients and methods

From 1990 to 2008, 210 patients were treated by NACT, RT and mastectomy with IBR for OIBC. One hundred and seven patients underwent a latissimus dorsi flap with implant (LDI), 56 patients a transverse rectus abdominis musculocutaneous (TRAM) flap, 25 an autologous latissimus dorsi flap (ALD) and 22, a retropectoral implant (RI) reconstruction.

Results

Forty-six (21,9\%) early events were recorded: 20 necrosis, 9 surgical site infections and 6 haematomas, requiring further surgery in 23 patients. More necrosis were observed with TRAM flap reconstructions $(p=0,000004)$, requiring more surgical revision than LD reconstructions. Seromas represented $42 \%$ of early complications in LD reconstructions. Fifty-five patients presented with late complications $(26,2 \%)$ with mainly implant complications (capsular contracture, infection, dislocation, deflation) $(23,6 \%)$, requiring reintervention in 14 cases. There were more delayed surgical revisions in $\mathrm{RI}$ reconstructions $(p=0,0005)$. The 5 years overall and disease-free survival rates were respectively $86,7 \%$ and $75,6 \%$. Sixty-four patients presented at least one recurrence (30,5\%) with 5 local , 9 locoregional and 54 distant relapses.

Conclusion

This therapeutic sequence does not seem to increase the IBR morbidity nor alter disease-free and overall survival. 


\section{Keys words}

Breast cancer

Mastectomy

Breast reconstructive surgery chemotherapy

radiotherapy 
Abbreviations, according to apparition in the text:

Immediate breast reconstruction: IBR

Neoadjuvant chemotherapy: NACT

Radiotherapy: RT

Operable invasive breast cancer: OIBC

Latissimus dorsi flap with implant: LDI

Transverse rectus abdominis musculocutaneous flap: TRAM flap

Autologous latissimus dorsi flap: ALD flap

Retropectoral implant: RI

Breast conservative surgery: BCS

In situ ductal carcinoma: DCIS

Locally advanced breast cancer: $L A B C$

Local recurrence: LR

Regional nodal recurrence: RNR 


\section{INTRODUCTION}

Neoadjuvant chemotherapy (NACT) in operable invasive breast cancer (OIBC) has been shown to increase breast conservation surgery (BCS). However, chemoresistant and multifocal tumours still require a mastectomy. As a consequence, today global management of these patients may include a breast reconstruction.

During the last decade, several studies have shown the advantage of immediate breast reconstruction (IBR) over delayed reconstruction in terms of cosmetic, quality of life and psychological aspects. ${ }^{1}$ Oncological safety of IBR has been confirmed when performing mastectomies for in situ ductal carcinoma (DCIS) and early-stage invasive breast cancers. ${ }^{2,3}$ However, the management of operable locally advanced breast cancer (LABC) (stage IIb and III) is challenging and includes a multimodal approach with systemic therapy, radiotherapy (RT) and surgery. The ability to safely integrate postmastectomy RT into the reconstructive algorithm has become more complex and controversial. Moreover, postmastectomy RT indications have been expanded following the results of several randomized trials. ${ }^{4,5}$

The ASCO guidelines have concluded that there is insufficient evidence to propose definitive recommendations with respect to the integration of postmastectomy RT and breast reconstruction. Clearly, the need for RT cannot always be definitively established before surgery and postoperative RT seems to increase the rate of surgical complications as well as impact upon cosmetic results. Moreover, RT seems to be more difficult after reconstruction leading to some controversies. $^{6,7}$

For patients with OIBC, eligible for mastectomy, CT and RT, we designed a different approach in order to match the patient's desire for IBR and the oncologic goals of the treatment. Hence, we decided to perform IBRs at the end of the therapeutic sequence after completion of CT and RT. This strategy, developed and used since 1990 in our institution, has allowed us to propose IBR to a larger number of patients, without interfering with CT and RT. The objectives of this retrospective study were to evaluate the incidence of local complications as well as the impact on the locoregional control of the disease, when using this strategy. 


\section{PATIENTS AND METHODS}

We retrospectively studied the medical records of patients treated for OIBC at the Jean Perrin Cancer Centre from 1990 to 2008. All women with primary OIBC requiring mastectomy, CT and $\mathrm{RT}$ and desiring IBR were included in this study. Patients with local recurrence as well as T4 or inflammatory cancer were excluded. A total of 210 patients with clinical stage 0 to III disease were eligible for analysis.

Diagnosis and staging were based upon clinical examination, mammography and ultrasonography of the breast and axillary area. Histopathological characteristics were initially confirmed for all patients using core needle biopsies and patients with palpable lymph nodes underwent axillary fine-needle aspiration cytology. The oncologic management was defined for each patient by a multidisciplinary committee in accordance with current therapeutic guidelines.

Two different cohorts of patients were identified: The first cohort was comprised of patients eligible for NACT, based upon core biopsy characteristics and clinical presentation (mostly large tumors). A mastectomy was performed because of multicentric disease, central location, large associated DCIS component or poor response to NACT. This cohort also included patients with clinical response to NACT but with failure of the BCS to get free margins for invasive or DCIS components.

The second cohort included women initially treated by BCS but requiring a secondary mastectomy in view of positive margins.

In both cohorts, the mastectomy with IBR was performed after CT and RT.

CT regimens varied over the studied period but all patients received anthracycline-based CT. Taxanes were introduced in our institution from 1997 onward (139 patients). HER2-neu status has been routinely determined since 1999 [119 patients]. Patients with HER2-neu abnormalities received neoadjuvant and/or adjuvant Trastuzumab treatment for 12 months. Therapeutic response to NACT was assessed by clinical examination and mammography with ultrasonography after 3 and 6 cycles of systemic therapy.

RT was indicated in keeping with current guidelines according to tumour size, multicentric disease, lympho-vascular invasion and axillary nodes status. All patients received RT from a Cobalt unit or a $6-\mathrm{MeV}$ linear accelerator, starting 4 to 6 weeks after completion of CT. The breast was treated with two opposing tangential fields. All patients received a total of 50 Gy on the whole breast and chest wall, over a fiveweek period with a daily target dose of 2 Gy. A boost dose to the tumour was usually delivered with an orthovoltage unit (10 Gy in five fractions).

Surgery was planned 6 to 8 weeks after completion of RT. The type of reconstruction was chosen according to the patients body image. Radical non-skinsparing mastectomy with level I and II axillary dissection and IBR were both performed by experienced oncological breast surgeons or in collaboration with a plastic surgeon.

Reconstruction technics were:

- transverse rectus abdominis musculo-cutaneous (TRAM) flap

- latissimus dorsi musculo-cutaneous flap with implant (LDI)

- autologous latissimus dorsi musculo-cutaneous (ALD) flap

- retropectoral implant $(\mathrm{RI})$

TRAM flaps were all unipedicled. For RI reconstruction, skin closure was associated with abdominal advancement flap. 
years.

Patients with positive hormone receptors received hormone therapy for 5

Surgeons evaluated postoperative outcomes at 2 weeks and 1 month and as frequently as necessary in case of complications. Complications were classified "early" when occurring within the first 30 days post reconstruction and "delayed" after 1 month. We reviewed anterior thoracic wall skin necrosis, flap necrosis, fat necrosis, wound hematoma, infection, capsular contracture and abdominal wall hernia. Infection was reported only when requiring hospitalization for intravenous antibiotic therapy or surgical revision. Additionally, dorsal seroma, lymphoedema, functional discomfort and chronic pain were also recorded. Reconstruction failure was defined as breast reconstruction being abandonned. Pure aesthetic secondary procedures were not taken into account.

Local recurrence (LR) was defined as any histologically-proven recurrent tumor on the site of the mastectomy and/or the flap. Ipsilateral axillary nodal relapse was classified as regional nodal recurrence (RNR). All other sites of recurrence were classified as distant metastases except contralateral disease.

Follow-up included clinical exam every six months, mammography and ultrasonography every year. In case of suspicion of local or distant relapse, a new clinical and iconographic evaluation, a CA 15.3 dosage and a core-needle biopsy were performed.

Comparisons of percentages were performed using the Chi-square test and comparison of means, using the t-test or the $\mathrm{H}$-test of Kruskal-Wallis, depending upon the normality of distributions and the homogeneity of variances. Overall survival was calculated from the date of surgery to the date of death, whatever the cause, and disease-free survival from the date of surgery to the date of relapse, whatever the type. Actuarial survival was calculated using the Kaplan-Meier's method. A pvalue $\leq 0.05$ was considered significant. 


\section{RESULTS}

A total of 210 patients were analysed, 135 in Cohort I, including 23 patients with BCS failure after NACT, and 75 patients in Cohort II. The mean follow-up was 8 years (1-20). Five patients were lost to follow-up. Clinical and tumor characteristics are summarized in Table 1. Tumor classification after lumpectomy for Cohort II is reported in Table 2.

All patients received 6 cycles of CT (average 4-12). The median interval time between completion of RT and surgery was 51,7 days [8-280], with no difference between the two groups $(p=0,08)$. One hundred and forty seven patients were treated with adjuvant hormone treatment.

Surgical procedures are summarized on table 3. Operation times and postopstay diverged significantly between $\mathrm{Rl}$ and musculo-cutaneous flap reconstructions $(p=0,0000086)$. There was no difference between LD and TRAM flaps $(p=0,40)$. Pathologic findings on mastectomy specimens showed a 35,2 \% complete histological response rate while there was no therapeutic effect in $2,9 \%$ of cases.

Table 4 is listing 46 early complications. There was no significant difference between the two cohorts $(p=0,25)$. Early complications were more frequent in the TRAM group $(33,9 \%)$ (RR TRAM vs. other reconstructions $=1,9[1,2-3,2] ; p=0,01$ ) with more necrosis (RR TRAM vs. others $=6,4$ [2,9-14,2]; $p=0,000004$ ). A trend towards more infections was noted for reconstructions with implant (LDI and RI) (RR LDI+I vs. TRAM+ALD = 5,0 [0,8-31,3]; $p=0,17)$. Twenty-three patients required surgical revision, mainly for necrosis resection $(43,5 \%)$ or implant removal $(30,4 \%)$. One patient needed further surgery following a complete TRAM necrosis. TRAM flaps required more surgical revision ( $R R$ TRAM vs. others $=2,5[1,2-5,3] ; p=0,015$ ), mainly for partial necrosis resection (Table 4).

Delayed complications were recorded in 55 patients, requiring surgical revision for 14 of them (Table 5). There was no difference between the two cohorts $(p=0,23)$. There were more delayed complications and more surgical revisions in the group RI $(27,3 \%, R R$ RI vs. others $=6,4$ [2,6-15,6]; $p=0,0005)$. Considering all complications, TRAM and $\mathrm{RI}$ reconstructions required more surgical revisions than LD reconstructions (RR TRAM vs. $L D=2,7[1,4-5,3]$ and $R R$ RI vs. $L D=4,2[2,0-8,6]$; $\mathrm{p}=0,0006)$. Twelve reconstruction failures were noted with 1 complete TRAM flap loss and 11 implants removal (6 in LDI and 5 in RI).

Patient overweight was significantly correlated to an increased risk of early complications (RR overweight vs. no overweight $=2,0[1,3-3,0] ; p=0,0009$ ). Smoking was not found, in our study, as being a risk factor for early or delayed complications (respectively, $p=0,20$ and $p=0,25$ ).

To date, 165 patients are alive with 158 of them without evidence of disease. Five and 10 years overall survival rates are respectively $83,5 \%$ and $66,7 \%$ for cohort I and $91,8 \%$ and $89,8 \%$ for cohort II $(p=0,006)$. Five and 10 years disease-free survival rates are respectively $71,6 \%$ and $59 \%$ for cohort I and $86,4 \%$ and 80,1 for cohort II $(p=0,012)$. Sixty four patients presented with at least one recurrence and we recorded 5 LR, 9 RNR and 54 distant relapses. Among patients with LR, only one had an isolated relapse (cohort I) while 2 patients presented with both local and metastatic relapses (cohort I) and 2 patients with synchronous local, loco regional and metastatic relapses (1 in cohort I and 1 in cohort II). Among RNR, two were isolated ( 1 in cohort I and 1 in cohort II) and five were associated with metastatic relapses (2 in the first cohort and 3 in the second). No significant difference in terms of LR and RNR was seen between the two cohorts ( $p=0,40$ and $p=0,79$ respectively). 
However, there were more metastatic recurrences in the first cohort compared to the second one (43 vs $11 \mathrm{p}=0,009$ ). 


\section{DISCUSSION}

Considerable variations in postoperative complications after IBR have been previously reported. These discrepancies may be related to study populations, previous treatments and their timings, reconstruction types and follow-up periods. We report here the morbidity and survival results of an original treatment algorithm for 210 patients with early and $\angle A B C$ requiring multimodal management, all treated in a similar manner.

The interpretation of data in regard to the effect of CT and RT on IBR is difficult because of the inability to compare series according to the variety of radiotherapeutic techniques and the different timings between RT and surgery. RT following NACT may be delivered in chemoresistant disease in the hope that modified radical mastectomy may become possible. The published data are scarce when considering the toxicity aspects of this approach. Huang reported the complications of non skin-sparing mastectomies in 32 patients treated by NACT and preoperative $\mathrm{RT}^{8}$ Among these, 10 patients required myocutaneous reconstructions (3 TRAM flaps, 6 LD flaps and 1 gluteal flap). There was a significant 53\% postoperative morbidity rate with wound infection (12,5\%), wound dehiscence $(6,3 \%)$ and flap necrosis $(6,3 \%)$. However, IBR data were not specified. Reoperation was performed in $13 \%$ of cases. These results are comparable to our results and reported data. $^{9}$

When postoperative RT may be required, most authors discourage IBR and the use of prosthetic materials. Several studies have suggested that postoperative RT increases reconstruction complications and affects cosmetic outcomes. ${ }^{10}$ The common practice consists of recommending delayed reconstruction or autologous myocutaneous flaps reconstruction ${ }^{6}$. However, results in regards of RT and IBR remain controversial. Pinsolle reviewed the morbidity of 266 LD flap and RI IBR. ${ }^{11}$ Sixteen percent of patients had previous RT. RT performed after reconstruction increased the capsular contracture rate. Preoperative RT did not increase the necrosis rate when compared to postoperative RT. In another study, Williams reported the complication rates after irradiation of 19 pedicled TRAM flaps compared to a group with delayed TRAM flaps performed after RT and a control group of TRAM flaps without any radiation history. ${ }^{12}$ Overall the flap complication rates were comparable when RT was delivered preoperatively or postoperatively. For several authors, there is no difference in terms of TRAM flap complications whether performed before or after $\mathrm{RT} .{ }^{13}$ Cordeiro reviewed 68 patients who received RT after IBR with tissue expander. ${ }^{14}$ Although the RT increased the incidence of contracture and surgical complications, the authors concluded that both the rate of reconstructive success and patient satisfaction remained high. Constant et al published similar results for $\mathrm{RI}$ reconstructions. ${ }^{15}$

Whilst it is acknowledged that RT is not always comparable when considering doses, timing and patient tolerance, it is accepted that RT increases reconstruction complications. However, it appears that the complication rate may not be related to the timing of RT/surgery. Initial reports suggested a trend toward an increase in fat necrosis and fibrosis in patients receiving $\mathrm{RT}$ after reconstruction. But, further studies concluding that morbidity and aesthetic results with postoperative RT are acceptable, did not find a lower complication rates compared to preoperatively irradiated patients. Additionally, it is known that the aesthetic evaluation depends upon various scales used and patient satisfaction has been proven to be high with IBR. ${ }^{1,14,15}$ There are several arguments in favor of delivering RT before breast reconstruction. First, a 
meta-analysis showed an increased mortality rate when delaying RT more than 6 months from the start of CT. ${ }^{16}$ RT before surgery may avoid the risk of delayed irradiation secondary to IBR complications. Secondly, RT is more difficult on a reconstructed breast. ${ }^{6,7}$ Thirdly, $\mathrm{RT}$ may alter the local microcirculation and collagen synthesis, potentially responsible for a progressive fibrosis. ${ }^{17,18}$ Thus, it may be more appropriate to perform a reconstruction as soon as possible after the completion of $\mathrm{RT}$ in order to avoid the inflammatory reactions.

In our series, complication rates and surgical revisions occurred more frequently in TRAM flap and RI reconstructions. Watterson reviewed 729 pedicled TRAM flaps. In this study, chest wall irradiation resulted in a statistically significant increase in both fat necrosis and flap necrosis. ${ }^{19}$ Bipedicled flaps showed a reduced risk of necrosis, suggesting that improved blood supply may overcome some of the effects of RT. Moreover, internal mammary lymph nodes are frequently irradiated in postmastectomy RT. This fact may have a negative impact, especially on pedicled TRAM flaps and could partly explain our morbidity rate. Tribondeau in 53 TRAM flap IBR and 62 delayed TRAM flap, reported a 30\% rate of surgical revisions of which $16,5 \%$ were due to necrosis. ${ }^{20}$ Among these patients, $52,6 \%$ did not receive any preoperative RT. As a consequence, for women with previous RT, some authors prefer TRAM-free flaps for improved blood supply through the inferior epigastric vessels and less tension on the vascular pedicle. ${ }^{21}$ Additionally, we observed one early skin necrosis in $\mathrm{RI}$ reconstructions. According to other studies, the main complications are infection and capsular contracture. ${ }^{11,15}$ In our series, LD group events represented $54,5 \%$ of all complications but only $9,8 \%$ required surgical revision. Complications occurred more frequently in the LDI group (44,6\%), related to implant complications. In another series who underwent reconstruction by LD flaps, the incidence of complications requiring a reoperation was $37 \%$. No differences were reported for delayed reconstruction vs. IBR or for patients receiving or not RT. ${ }^{22}$ We did not investigate the cosmetic and quality of life aspects in our series.

Today, there is a trend to perform skin sparing mastectomy with IBR in order to improve the cosmetic results. Numerous authors have reported the oncological safety of this procedure including patients with LABC. ${ }^{23}$ However, there are limited data regarding morbidity for patients who received CT and RT. Complication rates after skin sparing mastectomy and IBR for BCS with adjuvant RT failure appear to be acceptable but series are hampered by their small sample size. ${ }^{24}$ Overall, data on complication rates after postoperative RT appears to be inconclusive. ${ }^{25}$

It has been suggested that IBR might delay LR diagnosis. However, several studies have shown that IBR does not adversely affect disease-free nor overall survival and does not significantly delay the diagnosis of recurrent disease. ${ }^{26}$ Moreover, specific survival could be better in IBR patients than in patients without reconstruction. ${ }^{27}$ In our study LR and RNR rates were comparable with data from the literature suggesting that our strategy does not alter the loco regional control. ${ }^{28,29}$ Survival rates were significantly different between our 2 cohorts, mostly related to an obvious difference in prognosis factors. Taking these aspects into account, we did not observe any significant difference in terms of LR and RNR. Moreover, LR were rarely isolated and were usually concurrent with metastatic relapses suggesting a good loco regional control. 


\section{CONCLUSION}

As NACT may increase the conservative surgery rates for breast cancer, some patients still require a mastectomy. Today, IBR should be integrated in the global management of patients even if $\mathrm{RT}$ is indicated. We report the results of an innovative approach performing IBR after completion of CT and RT. This therapeutic sequence allowed to maintain the indication of IBR when RT was mandatory in order to avoid the risk of delaying the adjuvant treatment which could be secondary to reconstruction complications. With no additional morbidity and no negative impact on long-term survival, this sequence is feasible and oncologically safe for a selected group of patients. More morbidity data on skin sparing mastectomy in patients treated by CT and RT are needed. Recently, a team prospectively applied our concept in a small series of patients confirming our results. ${ }^{30}$ However, our findings need to be confirmed by larger prospective studies, including aesthetic and quality of life evaluation, before proposing this approach in routine clinical practice. 


\begin{tabular}{|c|c|c|c|}
\hline & COHORT I n=135 & COHORT II $n=75$ & $\mathbf{p}$ \\
\hline MEAN AGE (years) & 44,3 & 45,8 & 0,16 \\
\hline OVERWEIGHT (BMI>25) & 28 & 13 & 0,50 \\
\hline SMOKERS & 29 & 17 & 0,87 \\
\hline Initial clinical staging (AJCC)* & & & $<10^{-7}$ \\
\hline Stage I & 6 & 40 & 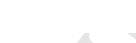 \\
\hline Stage IIA & 39 & 28 & \\
\hline Stage IIB & 50 & 4 & a \\
\hline Stage IIIA & 39 & 0 & $\nabla$ \\
\hline Stage IIIC & 1 & 0 & y \\
\hline \multicolumn{4}{|l|}{ Initial clinical tumor staging (TNM) } \\
\hline $\mathrm{T} 0^{* *}$ & 3 & 21 & \\
\hline $\mathrm{T} 1$ & 7 & 28 & \\
\hline $\mathrm{T} 2$ & 79 & 23 & \\
\hline $\mathrm{T} 3$ & 45 & 2 & \\
\hline \multicolumn{4}{|l|}{ Initial clinical axillary involvement* } \\
\hline No & 52 & 65 & \\
\hline $\mathrm{N} 1$ & 81 & 8 & \\
\hline $\mathrm{N} 2$ & 1 & 0 & \\
\hline N3 & 1 & 0 & \\
\hline Histological type $\mathbf{e}^{* * *}$ & & & 0,59 \\
\hline $\mathrm{CCI}$ & 108 & 55 & \\
\hline CLI & 22 & 16 & \\
\hline Other & 5 & 2 & \\
\hline SBR grading*** & & & 0,0008 \\
\hline I & 21 & 27 & \\
\hline II & 81 & 27 & \\
\hline III & 29 & 20 & \\
\hline \multicolumn{4}{|l|}{ Receptor status*** } \\
\hline $\mathrm{RE}+$ & 96 & 53 & 0,92 \\
\hline RE - & 35 & 20 & \\
\hline $\mathrm{RP}+$ & 77 & 47 & 0,30 \\
\hline RP - & 54 & 24 & \\
\hline HER2-neu status $* * *$ & & & 0,82 \\
\hline Positive & 15 & 4 & \\
\hline Negative & 60 & 22 & \\
\hline Unknown & 2 & 16 & \\
\hline
\end{tabular}


*Data were missing for 3 patients of the cohort II

** T0: unpalpable tumor

${ }^{\star * *}$ Histological characteristics result from core needle biopsy for group I and from surgical specimen for cohort II.

Table 1. Details of clinical and histological characteristics for each Cohort. 


\begin{tabular}{ccc}
\hline Histological stage & $\mathbf{N b}=\mathbf{7 3}^{\star}$ & $\begin{array}{c}\text { Details on axillary } \\
\text { involvement }\end{array}$ \\
\hline pT1pN0 & 12 & $1 \mathrm{mi}$ \\
pT1pN1 & 15 & $2 \mathrm{mi}+2 \mathrm{i}$ \\
pT2pN0 & 8 & \\
pT2pN1 & 17 & \\
pT3pN0 & 1 & \\
pT2pN2 & 3 & \\
pT3pN1 & 1 & \\
pT3pN2 & 5 & \\
pTxpN0 & 3 & \\
pTxpN1 & 1 & \\
pTxpN3 & 1 \\
pT1pNx & 3 \\
pT2pNx & 3
\end{tabular}

* Datas were missing for 2 patients in the cohort II (75). mi: micrometastasis

$\mathrm{i}$ : isolated tumor cells

Table 2. Tumoral classification from surgical specimen for Cohort II patients. 
Table 3. Surgical characteristics for each cohort.

\begin{tabular}{|c|c|c|c|c|}
\hline & $\begin{array}{c}\text { COHORT I } \\
n=135\end{array}$ & $\underset{n=75}{\text { COHORT II }}$ & \\
\hline MASTECTOMY INDICATION & & & \multicolumn{2}{|c|}{ NR } \\
\hline Multicentric & 62 & 16 & & \\
\hline Central & 10 & 0 & & \\
\hline Tumor volume/ Breast volume & 27 & 0 & & \\
\hline Extensive DCIS associated & 13 & 5 & & \\
\hline $\begin{array}{c}\text { Positive margin for invasive } \\
\text { component }\end{array}$ & $17 *$ & 36 & & \\
\hline Positive margin for DCIS component & $6^{*}$ & 18 & & \\
\hline MASTECTOMY TECHNIQUE & & & & \\
\hline Simple** & 23 & 61 & & \\
\hline $\begin{array}{l}\text { Radical modified with axillary } \\
\text { dissection }\end{array}$ & & 14 & & \\
\hline $\begin{array}{l}\text { RECONSTRUCTION } \\
\text { TECHNIQUE }\end{array}$ & & & OT & POS \\
\hline LDI & 67 & 40 & $251 \pm 75$ & $11,0 \pm 3,4$ \\
\hline TRAM & 41 & 15 & $310 \pm 102$ & $11,3 \pm 4,1$ \\
\hline ALD & 16 & 9 & $236 \pm 77$ & $12,3 \pm 4,1$ \\
\hline I & 11 & 11 & $148 \pm 55$ & $7,3 \pm 2,5$ \\
\hline & & & & 0,000009 \\
\hline
\end{tabular}

*Those 23 patients had an attempt of BCS after NACT

** axillary dissection in previous surgery

OT: Operation Time (mn); POS: PostOp Stay (days) 


\begin{tabular}{|c|c|c|c|c|c|}
\hline & $\begin{array}{c}\text { LDI } \\
\mathrm{n}=107\end{array}$ & $\begin{array}{c}\text { TRAM } \\
n=56\end{array}$ & $\begin{array}{c}\text { ALD } \\
n=25\end{array}$ & $\begin{array}{c}\mathrm{I} \\
\mathrm{n}=22\end{array}$ & $\begin{array}{c}\text { Total } \\
n=210\end{array}$ \\
\hline Necrosis & 2 & 14 & 3 & 1 & 20 \\
\hline Thoracic wall skin & 1 & 0 & 0 & 1 & \\
\hline Flap skin $<20 \%$ & 0 & 11 & 3 & 0 & \\
\hline Musculo-cutaneous & 1 & $1^{*}$ & 0 & 0 & \\
\hline Fat necrosis & 0 & 2 & 0 & 0 & \\
\hline Seroma & 8 & - & 2 & - & 10 \\
\hline Infection & 6 & 1 & 0 & 2 & 9 \\
\hline Hematoma & 3 & 3 & 0 & 0 & 6 \\
\hline Necrosis + Infection & 0 & 1 & 0 & 0 & 1 \\
\hline Total & 19 & 19 & 5 & 3 & $\begin{array}{c}46 \\
(21.9 \%)\end{array}$ \\
\hline Revisions & & & & & \\
\hline Necrosis resection & 0 & 9 & 1 & 0 & 10 \\
\hline Implant removal & 5 & - & - & 2 & 7 \\
\hline Hematoma drainage (HD) & 2 & 0 & 0 & 0 & 2 \\
\hline Infection drainage (ID) & 0 & 1 & 0 & 0 & 1 \\
\hline $\begin{array}{l}\text { Necrosis resection } \\
+ \text { Implant removal }\end{array}$ & 1 & - & - & 0 & 1 \\
\hline $\begin{array}{l}\text { Necrosis resection } \\
\text { +Infection drainage }\end{array}$ & 0 & 1 & 0 & 0 & 1 \\
\hline $\begin{array}{l}\text { Implant removal } \\
\text { +Infection drainage }\end{array}$ & 0 & - & - & 1 & 1 \\
\hline Total & 8 & 11 & 1 & 3 & 23 \\
\hline
\end{tabular}

* Complete flap necrosis.

Table 4. Early complications and surgical revisions depending on technique reconstruction. 


\begin{tabular}{|c|c|c|c|c|c|}
\hline & $\begin{array}{c}\text { LDI } \\
\mathrm{n}=107\end{array}$ & $\begin{array}{c}\text { TRAM } \\
\mathrm{n}=56\end{array}$ & $\begin{array}{c}\text { ALD } \\
\mathrm{n}=25\end{array}$ & $\begin{array}{c}\mathrm{I} \\
\mathrm{n}=22\end{array}$ & $\begin{array}{c}\text { Total } \\
\mathrm{n}=\mathbf{2 1 0}\end{array}$ \\
\hline Implant complications & 7 & - & - & 6 & 13 \\
\hline Capsular contracture & 4 & - & - & sina & ' \\
\hline Implant dislocation & 1 & - & - & & rata \\
\hline Implant deflation & 2 & - & - & & 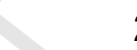 \\
\hline Implant infection & 0 & - & - & & $y$ \\
\hline Abdominal wall hernia & - & 6 & - & - & 6 \\
\hline Necrosis & 0 & 2 & 0 & 0 & 2 \\
\hline Lymphoedema & 8 & 4 & 1 & 2 & 15 \\
\hline Functional discomfort & 5 & 0 & 0 & 0 & 5 \\
\hline Chronic pain & 5 & 2 & 2 & 1 & 10 \\
\hline Seroma & 0 & 0 & 1 & - & 1 \\
\hline Lymphoedema & 1 & 1 & 1 & 0 & 3 \\
\hline Total & 26 & 15 & 5 & 9 & 55 \\
\hline Revisions & & & & & \\
\hline Implant removal & 0 & - & - & 2 & 2 \\
\hline Implant revision & 4 & - & - & 3 & 7 \\
\hline Infection drainage & 0 & 0 & 0 & 1 & 1 \\
\hline Necrosis resection & 0 & 2 & 0 & 0 & 2 \\
\hline Abdominal wall hernia & - & 2 & - & - & 2 \\
\hline Total & 4 & 4 & 0 & 6 & 14 \\
\hline
\end{tabular}

Table 5. Delayed complications and surgical revisions depending on the reconstruction technique. 


\section{REFERENCES}

1. Fernández-Delgado J, López-Pedraza MJ, Blasco JA and al. Satisfaction with and psychological impact of immediate and deferred breast reconstruction. Ann Oncol 2008; 19: 1430-4.

2. Nonne RB, Murphy JB, Spear SL and al. A six-year experience with immediate reconstruction after mastectomy for cancer. Plast Reconstr Surg 1985; 76: 258-69.

3. Georgiade GS, Riefkohl R, Cox E and al. Long-term clinical outcom of immediate reconstruction after mastectomy. Plast Reconstr Surg 1985; 76: 415-20.

4. Overgaard $M$, Hansen PS, Overgaard L and al. Postoperative radiotherapy in highrisk premenopausal women with breast cancer who receive adjuvant chemotherapy. N Engl J Med 1997; 337: 949-55.

5. Overgaard $\mathrm{M}$, Jensen $\mathrm{MB}$, Overgaard $\mathrm{J}$ and al. Postoperative radiotherapy in highrisk postmenopausal breast-cancer patients given adjuvant tamoxifen: Danish Breast Cancer Cooperative Group DBCG 82c randomised trial. Lancet 1999; 353: 1641-48.

6. Kronowitz SJ, Robb GL. Radiation therapy and breast reconstruction: a critical review of the literature. Plast Reconstr Surg 2009; 124: 395-408.

7. Motwani SB, Strom EA, Schechter NR and al. The impact of immediate breast reconstruction on the technical delivery of postmastectomy radiotherapy. Int $\mathrm{J}$ Radiat Oncol Biol Phys 2006; 66: 76-82.

8. Huang E, Mcneese MD, Strom EA and al. Locoregional treatment outcomes for inoperable anthracycline-resistant breast cancer. Int J Radiat Oncol Biol Phys 2000 ; $53: 1225-33$.

9. Sauter ER, Eisenberg BL, Hoffman JP and al. Postmastectomy morbidity after combination preoperative irradiation and chemotherapy for locally advanced breast cancer. World J Surg 1993; 17: 237-41.

10. Kaufmann M, Hortobagyi GN, Goldhirsh A and al. Recommandations from an international expert panel on the use of neoadjuvant (primary) systemic treatment of operable breast cancer: an update. J Clin Oncol 2006; 24: 1940-9.

11. Pinsolle V, Grinfeder $C$ and al. Complications analysis of 266 immediate breast reconstructions. Journal of Plastic, Reconstructive and Aesthetic Surgery 2006; 59: 1017-24.

12. Williams JK, Carlson GW and al. The effect of radiation treatment after TRAM flap reconstruction. Plast Reconstr Surg. 1997; 100: 1153-60. 
13. Carlson GW, Page AL, Peters $\mathrm{K}$ and al. Effects of radiation therapy on pedicled transverse rectus abdominis myocutaneous flap breast reconstruction. Ann Plast Surg 2008; 60: 568-72.

14. Cordeiro PG, Pusic AL, Disa JJ and al. Irradiation after immediate tissue expanders/ implant breast reconstruction: outcomes, complications, aesthetic results and satisfaction among 156 patients. Plast Reconstr Surg 2004 ; 113: 877-81.

15. Contant C.M.E., van Geel AN, van der Holt B and al. Morbidity of immediate breast reconstruction after mastectomy by a subpectorally placed silicone prosthesis: the adverse effect of radiotherapy. Eur J Surg Oncol 2000; 26: 344-50.

16. Whelan $\mathrm{TJ}$, Julian $\mathrm{J}$, Wright $\mathrm{J}$ and al. Does locoregional radiation therapy improve survival in breast cancer? A meta-analysis. J Clin Oncol 2000; 18: 1220-9.

17. Dubray B, Delanian S, Lefaix JL. Late effects of mammary radiotherapy on skin and subcutaneous tissues. Cancer Radiother 1997; 1: 744-52.

18. Keskikuru R, Jukkola $A$, Nuutinen $\mathrm{J}$ and al. Radiation-induced changes in skin type I and III collagen synthesis during and after conventionally fractionated radiotherapy. Radiother Oncol 2004; 70: 243-8.

19. Watterson PA, Bostwick $\mathrm{J} 3^{\text {rd }}$, Hester TR $\mathrm{Jr}$ and al. TRAM flap anatomy correlated with a 10-year clinical experience with 556 patients. Plast Reconstr Surg 1995; 95: 1185-94.

20. Tribondeau P, Soffray F. Reconstruction mammaire par lambeau musculocutané unipédiculé de muscle grand droit de l'abdomen (115 cas consécutifs). Ann Chir Plast Esthet 2007; 53: 309-17.

21. Paige $\mathrm{KT}$, Bostwick $\mathrm{J} 3^{\text {rd }}$, Bried $\mathrm{JT}$ and al. A comparison of morbidity from bilateral, unipedicled and unilateral, unipedicled TRAM flap breast reconstructions. Plast Reconstr Surg 1998; 101: 1819-27.

22. Roy MK, Shrotia S, Holcombe $C$ and al. Complications of latissimus dorsi myocutaneous flap breast reconstruction. Eur J Surg Oncol 1998; 24: 162-5.

23. Downes KJ, Glatt BS, Kanchwala SK and al. Skin-sparing mastectomy and immediate reconstruction is an acceptable treatment option for patients with high-risk breast carcinoma. Cancer 2005; 103 : 906-13.

24. Disa JJ, Cordeiro PG, Heerdt $\mathrm{AH}$ and al. Skin-sparing mastectomy and immediate autologous tissue reconstruction after whole-breast irradiation. Plast Reconstr Surg 2003; 111: 118-24.

25. Reefy S, Patani N, Anderson A and al. Oncological outcomes and patient satisfaction with skin-sparing mastectomy and immediate breast reconstruction : a prospective observational study. BMC Cancer 2010; 10: 171. 
26. Noguchi M, Earashi $\mathrm{M}$, Ohta $\mathrm{N}$ and al. Mastectomy with and without immediate breast reconstruction using a musculocutaneous flap. Am J Surg. 1993; 166: 279-83.

27. Bezuhly M, Temple C, Sigurdson LJ et al. Immediate postmastectomy reconstruction is associated with improved breast cancer-specific survival. Cancer 2009; 115: 4648-54.

28. Huang CJ, Hou MF, Lin SD and al. Comparison of local recurrence and distant metastases between breast cancer patients after postmastectomy radiotherapy with and without immediate TRAM flap reconstruction. Plast Reconstr Surg. 2006; 118: 1079-86.

29. Sandelin K, Wickman M, Billgren AM. Oncological outcome after immediate breast reconstruction for breast cancer: a long-term study. The Breast 2004; 13: 2108.

30. Giacalone PL, Rathat G, Daures JP, Benos P, Azria D, Rouleau C. New concept for immediate breast reconstruction for invasive cancers: feasability, oncological safety and esthetic outcome of post-neoadjuvant therapy immediate breast reconstruction versus delayed breast reconstruction: a prospective pilot study. Breast Cancer Res Treat. 2010; 122: 439-51. 
Acknowledgements:

We would like to congratulate Fabrice Kwiatkowski for the statistical analysis and Alison Thompson from Saint Bartholomew Hospital (London) for reviewing our paper. 